NBER WORKING PAPER SERIES

\title{
DEFAULT RISK SHARING BETWEEN BANKS AND MARKETS: THE CONTRIBUTION OF COLLATERALIZED DEBT OBLIGATIONS
}

\author{
Günter Franke \\ Jan Pieter Krahnen \\ Working Paper 11741 \\ http://www.nber.org/papers/w11741 \\ NATIONAL BUREAU OF ECONOMIC RESEARCH \\ 1050 Massachusetts Avenue \\ Cambridge, MA 02138 \\ November 2005
}

We are indebted to Dennis Hänsel, Thomas Weber and Christian Wilde for their excellent computational assistance and their comments which greatly helped us to improve the paper. Furthermore, we owe a lot to Mark Carey and René Stulz for their detailed and very helpful comments on earlier versions of this paper. We also gratefully acknowledge financial support by Deutsche Forschungsgemeinschaft and by the Center for Financial Studies at Frankfurt's Goethe University. The views expressed herein are those of the author(s) and do not necessarily reflect the views of the National Bureau of Economic Research.

(O2005 by Günter Franke and Jan Pieter Krahnen. All rights reserved. Short sections of text, not to exceed two paragraphs, may be quoted without explicit permission provided that full credit, including $\odot$ notice, is given to the source. 
Default Risk Sharing Between Banks and Markets: The Contribution of Collateralized Debt Obligations

Günter Franke and Jan Pieter Krahnen

NBER Working Paper No. 11741

November 2005

JEL No. D82, G21, D74

\section{$\underline{\text { ABSTRACT }}$}

This paper contributes to the economics of financial institutions risk management by exploring how loan securitization affects their default risk, their systematic risk, and their stock prices. In a typical CDO transaction a bank retains through a first loss piece a very high proportion of the default losses, and transfers only the extreme losses to other market participants. The size of the first loss piece is largely driven by the average default probability of the securitized assets. If the bank sells loans in a true sale transaction, it may use the proceeds to expand its loan business, thereby affecting systematic risk. For a sample of European CDO issues, we find an increase of the banks' betas, but no significant stock price effect around the announcement of a CDO issue.

Günter Franke

Center for Finance and Econometrics

at the University of Konstnaz

guenter.frnake@uni.konstanz.de

Jan Pieter Krahnen

Goethe-University Frankfurt 


\section{$1 \quad$ Introduction $^{1}$}

In recent years securitization of loan and bond portfolios became more and more popular among banks. The volume of collateralized loan obligations (CLOs) and collateralized bond obligations (CBOs) strongly increased in the US and in Europe. This development raises several issues at the micro- and the macro level. This paper will address some issues on the micro level, in particular the impact of CLO-transactions on the banks' risk taking.

In a CLO-transaction the bank transfers default risks of the underlying loans to other market participants, the investors. Since the bank usually has inside information about its borrowers, it has to offer some credit enhancements in a CLO-transaction to protect the investors against potential effects of asymmetric information. For that purpose the bank usually takes a first loss position in the default risks of the underlying loan portfolio. This raises the question about the effective extent of the risk transfer in a CLOtransaction. The first purpose of this paper is to look into this issue.

Our results show, first, that contrary to what many observers believe, the default losses of the securitized portfolio largely remain on the books of the issuing bank. Second, in a fully funded transaction, the risk of extreme unexpected losses, i.e. the bad tail risk, is transferred from the bank to investors. We argue that the combined effect of retaining the first loss piece and selling senior tranches to investors achieves an efficient risk allocation, reducing the bank's exposure to extreme risks which might endanger the bank's solvency. Thus, securitization should have a positive impact on the bank's solvency.

This direct effect of securitization on the bank's default risk is derived from simulations of the loss rate distribution of the underlying loan portfolio. This distribution and the first loss position jointly determine the eventual risk transfer to investors. The loss rate distribution depends not only on the average quality of the underlying loans, but also on the correlation of defaults among these loans. Therefore the correlation impact is also analyzed in the simulations.

Banks usually securitize loan portfolios not only for their direct effect, but also to enlarge their investment opportunity set. In a fully funded transaction the bank can use the proceeds from issuing securities in various ways. The most conservative use would be to reinvest the proceeds in risk-free assets or to repay some of its own debt. In this case, securitization would reduce the overall risk of the bank. Alternatively, the bank could expand its loan business by granting new loans to new customers. Then the bank would retain the default risk of the first loss position and, in addition, take the default risks of the new loans. Even though the total loan portfolio of the bank 
is now better diversified, the overall risk of the bank is likely to be higher than before securitization. We also simulate the effects of this reinvestment policy, assuming different correlations among the loan defaults. The simulation results indicate that the standard deviation of the bank's loan loss rate increases after securitization. Thus, it would be naive to assume that securitization generally reduces the banks' risks.

The nature of the bank's reinvestment policy is an empirical matter. Therefore, we try to obtain some insight into this question by analyzing the stock market reaction to securitization. This is the second main purpose of the paper. The underlying approach is based on the CAPM. In an event study we look at the abnormal stock returns of a bank around the announcement date of a securitization to find out whether the stockholders consider securitization as value enhancing. We also look at the bank's beta change around the securitization and try to infer from this change the nature of the bank's reinvestment policy. Obviously, such an approach is based on several assumptions. Therefore the conclusions are preliminary, at best. A more careful analysis needs to look at the details of the bank's balance sheets. But this is beyond the scope of this paper.

We find no significant abnormal stock returns around the announcement dates. But we find significant increases in the banks' stock betas. We interpret this as evidence that most banks use securitization to take more systematic risks. Suppose, for example, that banks use the proceeds from securitization in a fully funded transaction to grant new loans to new customers. Then the granularity of the bank's total loan portfolio should increase so that also the correlation between the bank's default losses and the macrofactor of default losses should increase. Assuming a strong correlation between the macrofactor of default losses and the stock market return and a strong correlation between the bank's default losses and its stock return, the correlation between the bank's stock return and the market return should increase. In addition, this reinvestment policy is likely to raise the standard deviation of the bank's default losses and, thus, the standard deviation of the bank's stock return so that the bank's beta should increase.

The finding that, on average, the banks' betas increase with securitization announcements could be explained not only by taking more systematic risks, but also by secular increases of banks' betas over the sampling period. However, we control for this possibility. Therefore, we regard our finding as preliminary empirical evidence about the banks' reinvestment policies.

These findings on the micro level can have important consequences on the macro level, in particular, on the stability of financial markets. We will comment on these potential effects only briefly in the conclusion.

The paper is organized as follows. In section 2, we first provide some 
institutional background and then analyze the securitization impact on the default risk of the bank's loan book. In section 3, we look at the stock market reaction to securitization annnouncements including the beta effects. Section 4 concludes.

\section{Tranching and the allocation of risk}

In section 2.1, the typical securitization contracts are briefly described. Moreover, based on a European sample of collateralized debt obligations (CDOs), some evidence on first loss pieces and tranching is presented. In section 2.2, we describe our method to simulate the default loss distribution for a given loan portfolio. Section 2.3 presents some European evidence on loss allocation to tranches in CDO-transactions. Section 2.4 then analyzes the effects on the bank's default losses of securitization and reinvestment policies.

\subsection{Basics of contract design}

There are basically two types of CDO transactions, fully funded asset backed securities (ABS) and synthetic transactions. For a detailed description of contract types see [13] (Chapters 24 and 25) and [7] (Part one). In an ABS transaction the bank sells part of its loan portfolio to a special purpose vehicle (SPV) which refinances itself through the issue of bonds. Usually the bank has to take a first loss position, i.e. the bank agrees to absorb default losses up to a specified limit. To achieve this, the bank can buy the nonrated tranche (equity tranche) which absorbs all default losses up to its par value, before other tranches have to bear any further losses. In addition or alternatively, the SPV can set up a reserve account which builds up over time from excess interest payments, received from the SPV after it has serviced other investors. The reserve account absorbs default losses in a similar way. In these transactions, the bank can use the proceeds from the sale of its loans to generate new business.

In a synthetic CLN (credit linked note) transaction, the bank retains the loans, but buys protection through a credit default swap with a SPV as the counterparty. Again, the bank usually takes a first loss position by arranging the swap so that nothing is paid unless losses on the underlying loan portfolio exceed a threshold. Moreover, the maximum amount paid by the swap is often much smaller than the face value of the underlying loan portfolio. The bank thus retains both a first loss position and the 
risk associated with very large losses. The bank may buy protection for these risks through a senior credit default swap with a different counterparty. A synthetic CLN arrangement differs from an ordinary credit default swap arrangement because the SPV's assets protect the bank against counterparty risk, may provide more regulatory capital relief, and may permit a widerthan-usual class of investors to act as protection sellers.

The first loss position is motivated by information asymmetries. These asymmetries are a major obstacle to trading debt claims, in particular claims against small obligors about whom little is known publicly [19]. Adverse selection and moral hazard of the bank create problems similar to those in the insurance business. Therefore, suitable mechanisms of protection are also applied in CDO transactions. The main instruments are first loss positions (deductibles in the case of insurance contracts) and risk sharing arrangements (coinsurance in the case of insurance contracts). First loss positions have been shown to be optimal arrangements in a number of papers, including [1], [31], [16]. [28] shows that splitting (tranching) the portfolio payoff into a risk-free security which is not subject to asymmetric information problems and sold to outside investors, and a risky asset which may be retained by the bank, is better than having one type of security only which is partially sold to outside investors. [8] generalizes this idea so that the tranches sold may also be risky. In a study on US credit card securitizations, [4] argue that even in the absence of a first loss piece retention, implicit recourse through early amortization may serve the same economic function, thereby circumventing minimum capital regulation.

[18] proposes a partial loan sale to mitigate moral hazard problems. This is observed in credit card securitizations, for example, but not in CLO transactions. The reason may be that the originator is likely to earn a higher fraction of expected monitoring benefits if he takes a high first loss position instead of retaining a moderate fraction of all tranches. Thus, investors may believe that a FLP provdes stronger monitoring incentives.

The first loss piece reduces problems of asymmetric information faced by investors if it is held by the originating bank. In principle, the bank can transfer the default losses of a first loss piece by buying a credit default swap or, in the case of an equity tranche, by selling this tranche. Usually banks do not publish information on this issue. An investigation of the Deutsche Bundesbank [9] covering the major ten German banks securitizing loan portfolios revealed that, on average, they retain not only the first loss piece amounting to 2.1 percent of the transaction volume, but in addition also the lowest rated tranches amounting to another 4.9 percent of the transaction volume. Thus, it appears, that the originating banks usually retain the first loss piece. This would be in line with economic reasoning since we would 
expect very high credit spreads required by investors for taking the default losses of the first loss piece due to asymmetric information.

The optimal size of the first loss position depends not only on problems of asymmetric information, but also on various other considerations. A larger first loss piece reduces the default loss transfer and absorbs more regulatory as well as economic equity capital leaving less room for new activities of the originating bank. Given the strong skewness of a typical loan portfolio's default loss distributions as illustrated in the next section, we would expect the first loss piece to clearly exceed the mean default loss.

The importance of default risk for the size of the first loss position (FLP) can be seen from a sample of 43 European CLO transactions, for which we could get a standardized measure of portfolio default risk.

This is done by converting Moody's weighted average rating factor or, if it is not available, the weighted average quality of the underlying loans into a weighted average default probability $(w a d p)$. We then regress the nominal size of the first loss piece on the weighted average default probability, the issue date, and Moody's diversity score $(d s)$. The latter statistic captures the diversification of the underlying asset portfolio. Its score is increasing if portfolio loans are spread more evenly within and across industries.

$f l p=c+\beta \cdot w a d p+\gamma \cdot d s+\delta \cdot$ date $+\varepsilon$

The regression result finds $\beta$ to be positive and highly significant ( $p=$ $0.00)$, while $\gamma$ is negative and weakly significant $(p=.07)$; the adjusted $\mathrm{R}$ squared is 0.73 . The issue date is insignificant. Thus, the weighted average default probability is a strong determinant of the size of the FLP, confirming our conjecture that the first loss position increases with the expected default loss of the underlying portfolio. The protective role of the FLP will become more apparent when, in the next section, we simulate the loss distribution of the underlying portfolio, and estimate the share of expected default losses covered by the first loss position.

The shape of the loss distribution is essential for understanding the relevance of the diversity score for the size of the first loss position. A large diversity score is indicative of a steep loss distribution, with loss observations being more heavily concentrated around the mode.

A common feature of asset securitizations is the allocation of portfolio risk to several layers of claims. These layered claims, or tranches, obey the principle of strict subordination. Losses up to the par value of the lowest tranche are completely absorbed by the holders of this tranche. If accumulated losses of the underlying asset portfolio exceed the par value of the lowest tranche, which is the detachment point of the tranche and the attachment point of the next senior tranche, the latter will absorb the remaining losses, up to its detachment point, and so on for the remaining tranches. In this 
way, tranches which are more senior will only be affected if default losses reach their attachment point, after having wiped out all junior tranches ${ }^{2}$.

According to the model in [15], optimal securitization design aims at a structure that facilitates funding of relationship specific assets by less informed ("remote") investors. Senior tranches are suited for these investors since, by construction, they are largely free of default risk, see [28] and [8]. Therefore, holders of senior tranches are rarely exposed to the moral hazard component of the underlying lending relationships. Investors need not spend resources on monitoring the underlying lending relationships, thus lowering the required tranche rate of return in equilibrium ${ }^{3}$. Issuing mezzanine tranches to relatively more sophisticated investors supports the reduction in delegation costs even further. These investors have an expertise in risk assessment and monitoring, providing a buffer between the first loss piece held by the issuer and the senior piece held by remote investors.

The number of distinct mezzanine tranches should therefore depend on the shape of the loss rate distribution. How does the number of tranches of a given transaction relate to the degree of diversification and the default probability of the underlying loan portfolio? An empirical estimate follows from regressing the number of tranches on Moody's diversity score and on the weighted average default probability:

\#tranches $=c+\beta \cdot$ wadp $+\gamma \cdot d s+u$

In a simple OLS regression using the same 43 European CLO transactions as before, we find that the diversity score has a positive and significant coefficient $(p=0.00)$, while wadp is insignificant. The adjusted R-squared is 0.2. Thus, after controlling for the default probability, a steeper loss rate distribution is associated with a higher number of mezzanine layers. Inclusion of the first loss piece and the issue date does not change the regression results.

The implications of [15] relate to the risk allocation achieved by tranching the underlying collateral portfolio. By acquiring the senior tranche, remote investors essentially take on macroeconomic risk. To be more precise, the payoff from holding a senior tranche is effectively indexed to systemwide macroeconomic shocks. Define the macrofactor of default risks as the average default rate on the aggregate portfolio of debt claims. This factor is random and, by definition, ranges in the $(0,1)$ interval. Then a well-diversified loan portfolio of average initial quality will only incur average default rates beyond, say, ten percent if the macrofactor is in the same range. Hence the senior tranches will only incur default losses if the macrofactor turns out to be very bad.

This is not to say that in a like situation there is no moral hazard of the bank. It may well be that in a severe downturn situation banks do not 
care much about their loans anymore. Moral hazard behavior may then be difficult to detect, so that reputational costs are low. Yet, the senior tranches are only impaired if the macrofactor turns out to be bad. If the macrofactor turns out to be good, then even strong moral hazard behavior is very unlikely to affect the senior tranches at all.

Thus, the structural aspects characterizing collateralized debt obligations are devised to solve the inherent tension that exists between the originator who has private information, and a diversified investor base without this information. Due to the informational disparity, the originator's claim is highly illiquid, and a direct sale of the asset would create a large discount relative to the going concern value of the asset, see [18] and [11].

In section 2.3 we will characterize the properties of junior and senior tranches, building on the information provided in the offering circulars of a large number of European CDO-transactions. This characterization requires knowledge of the loss rate distributions of the underlying portfolios, in particular the allocation of default losses to the various tranches. Whether the size of the first loss piece appears sufficient to mitigate problems of asymmetric information, depends on the shape of the loss distribution.

\subsection{Estimating the loss distribution}

To estimate the loss distribution of the underlying portfolio and the implied loss allocation to the various tranches, we proceed as follows. First, we use the information in the offering circular ${ }^{4}$ on the quality of the underlying loans and their initial portfolio weights, as indicated by a rating agency. If this information is not available, we use the average initial loan quality as indicated by a rating agency. Then we use $S \& \mathrm{P}^{\prime} \mathrm{s}$ transition matrix for different loan qualities to estimate the default probabilities for particular loans over the lifetime of the transaction: we use Monte Carlo simulation to generate a distribution of rating migration paths assuming a $47.5 \%$ recovery rate throughout. Absent better data on loss given default, these assumptions are standard in the literature.

Multi-year asset value migration tables are derived from the one-year table through repeated multiplication. The migration matrix is then mapped into a matrix of standard normal threshold values. For each asset, a random draw from the standard normal distribution yields a migration from the beginning of the year to the end of the year rating notch. To arrive at a portfolio return, the correlations between loan migrations need to be taken into account. This is done by a Cholesky transformation.

For assets in the same industry (in different industries), the correlation 
coefficient is initially set at $0.3(0.0)$, following common practice [29]. Alterations of the assumptions on asset correlations will later on be used to analyze the impact of systematic risk on loss correlations between tranches.

The generation of final portfolio cash flows and their allocation to the tranches that constitute the issue is achieved in a last step. The cash flows of each period $t$ are transformed in a realized final (compound) value, $R F V_{t}$, using a flat term structure of interest rates (4\%). If a credit event is recorded (default), then the assumed recovery is accounted for, and all further cash flows from this asset are set equal to zero. All final cash flows are allocated to tranches according to the cashflow waterfall-principle, as defined in the offering circular. Finally, for each tranche, the nominal claims of each period, $N V_{t}$, are transformed into a final value as well, $N F V_{t}$. The sum of these final values over all tranches defines the final value of all claims. The ratio of these two final values defines the portfolio loss rate, $P L R_{T}=1-\frac{\sum_{t} R F V_{t}}{\sum_{t} N F V_{t}}$. Using 50,000 observations, a loss distribution is generated that reflects the loss cascading inherent in the tranche structure ${ }^{5}$.

Figure 1 about here

Figure 1 shows the loss rate distribution of the London Wall 2002-2 transaction, issued by Deutsche Bank in 2002, which appears to be a typical example of a CDO transaction. Here we assume an intra-industry correlation of 0.3 , and a zero interindustry correlation. The graph shows a pronounced skewness. The expected loss is $150 \mathrm{bp}(1.5 \%)$ with a first loss position of $246 \mathrm{bp}$. By retaining the FLP, the originator bears all losses within the 91\%quantile of the loss rate distribution. Hence, a large fraction of losses is not transfered to investors, which serves as a strong barrier to adverse selection and moral hazard.

\subsection{Loss allocation in CDO transactions}

How is the risk of an underlying portfolio allocated to tranches? In particular, to what extent are losses, given the estimated probability distribution of loss rates, absorbed by the various tranches? In a typical issue, the first loss piece comprises between $2 \%$ and $10 \%$ of the issue volume, while the senior AAArated tranche comprises as much as $80-95 \%$. Further evidence is derived from looking at a sample of 40 European CDO-transactions with close to 150 tranches, see the list in Table 6 . This sample has some overlap with the CLO-sample used for the regressions in section 2.1.

In calculating the loss distributions for this European CDO sample, we rely on our own loss estimator, introduced in the last section. Given the loss distribution, we then take the ratings of the tranches from the offering circular 
and determine their attachment points. For this exercise we use $\mathrm{S} \& \mathrm{P}$ 's table indicating the estimated default probability of a claim for a given rating and a given maturity. This exercise starts with the most senior tranche, and ends with the lowest rated tranche. An AAA-claim with maturity of ten years, for example, has an estimated default probability of about 1 percent. Then the attachment point of this tranche is the (100 - 1)-percent quantile of the loss distribution. By the same procedure, the attachment points of the other rated tranches are derived. The unrated first loss piece is thus determined by the attachment point of the lowest rated tranche.

Table 1 summarizes the results of this mapping exercise ${ }^{6}$. The table presents average values by type of asset. We consider three asset classes, collateralized loan obligations (CLO) with large loans and bonds, CLOs with small corporate loans (SME-CLO), and the rest (other, including CBOs and portfolios of CDO tranches). These asset classes differ with respect to diversification and relationship intensity. First, the degree of diversification is low for CBOs and high for SME-CLO issues, while CLOs are somewhat in between, as evidenced by the average diversity scores. Second, the relationship character of the underlying lending relationship is probably highest in the case of the SME loans, and lowest in the case of CBOs, which typically comprise bonds issued by large caps.

Table 1 about here

Table 1 uses a broad classification of 40 European transactions issued between January 1999 and July 2002 . It is instructive to compare the second and the fourth column, SME-CLOs and CBOs, because the underlying assets differ. The former consists of bank loans extended to small and mid sized companies, while the latter refers to bonds issued by large corporates. The average quality of the loans is below that of the bonds. Not only is the average issue size of SME portfolios about $80 \%$ higher than that of the average CBO portfolio, but also the number of loans by far exceeds the number of bonds, suggesting that SME-CLOs are more granular, i.e. more diversified than CBOs. The table also shows that while the average size of the first loss piece is similar for both issue types ${ }^{8}$, it covers a much wider portion of the loss rate distribution in case of CBOs. The size of their FLPs is on average 3.36 times the expected loss of the underlying portfolio, and it is 1.34 times in case of SME-CLOs, although the difference in rating quality of the underlying portfolios is small. Due to the difference in first loss positions, the median rating of the most junior rated tranche of the CBO transactions is several notches higher than its counterpart among SME-CLO transactions. CBO-first loss pieces cover 0.96 of the cumulative density of the underlying portfolio's loss rate distribution, on average. The remaining risk to be 
allocated to investors is relatively small, allowing for only 2.85 additional tranches to be issued for CBOs. This number is significantly lower than in case of SME-CLOs where it reaches 4.57.

In all asset classes, the first loss piece covers more than $100 \%$ of the mean loss. Variations are sizeable, but there is no clear picture across asset classes. The average size of the first loss piece is $7.1 \%$, with a significant variation between non-SME-CLOs and CBOs. As a consequence, FLPs take over most of the losses, and the losses allocated to the senior tranche are restricted to extreme, systematic events. Their expected value is very low, $0.01 \%$ of the senior tranche volume on average, as is their default probability $(0.5 \%)$.

\subsection{Securitization effects on the bank's overall default risk}

While the previous section analyzes the allocation of default losses to different tranches, this section looks at the impact of securitizations on the bank's overall default risk. This is also essential for the stock return analysis in section 3. Assuming a true sale with all tranches being sold to outside investors, except the first loss piece, what are the consequences for the risk exposure of the bank? The answer depends on several aspects: first, what other assets does the bank have on its book and how are their cash flows and default risks correlated with those of the securitized loans? Second, what would be the effect of securitizing all default risks? Third, how does securitization change the bank's loan policy?

So far, there is little evidence on the impact of securitization on bank policy. Cebenoyan and Strahan [5] find mixed evidence on whether banks' risks increase with securitization. Regressing the banks' return volatility on securitization, they find positive (insignificant) and negative (significant) coefficients, depending on which other variables are included in the regression.

In order to improve our understanding, we consider a bank with a portfolio of 50 identical loans extended equally to obligors in 5 different industries, one year to maturity, and the same quality. The latter is set equal to a B rating, implying a $8.5 \%$ default rate [25]. The bank can either keep the loans in its books, or securitize them. For the securitized portfolio, the bank retains a non-rated tranche of 10.11 percent, i.e. a first loss position. The bank then reinvests the proceeds amounting to $(100-10.11)$ percent in new loans to obligors with the same quality characteristics as those in the initial loan book. Hence the on-balance sheet loan book of the bank, including the retained first loss piece, has the same size as before securitization. But the new loans are not perfect substitutes for the old loans because the new loans 
are granted to new obligors so that the granularity of the total loan portfolio increases.

This assumption of reinvestment represents a polar case of bank policy. The other polar case would be that the bank reinvests the proceeds from securitization in risk-free assets. In this case the bank would retain the risks of the first loss piece, but not incur new risks. For a highly rated bank the effects would be very similar to those of an early repayment of debt. In reality banks are likely to follow some route between these polar cases so that some new risks are added to the bank's portfolio.

Table 2 shows the first four moments of the distribution of loss rates (1) for the original loan portfolio without securitization and (2) for the new portfolio whose default losses are composed of those from the FLP of the securitized portfolio plus all default losses from the newly granted loans. The moments depend on the assumed intra- and interindustry correlations, therefore we report different correlation scenarios. In the first, the base case, intra-industry dependence is set at 0.3 , while inter-industry correlation is zero. The other scenarios assume a stronger dependency, suggesting the existence of a common systematic factor. Higher correlations reflect a stronger macrofactor of default risks.

Table 2 about here

First, consider the effect of securitization and reinvestment in the correlation base case. Figure 2 plots the difference between the default rate distribution of the new and that of the original portfolio. The graph indicates that securitization and reinvestment lower the default probabilities in the range 0 to $18 \%$, and raise them in the range 18 to $46 \%$. Therefore, the mean loss rate of the new portfolio is higher than the respective rate of the original portfolio. The ratio of the mean of the new portfolio over that of the original portfolio is not just $(1+(1-0.1011))=1.8989$, but clearly lower. The reason is that in the new portfolio the loss of the securitized portfolio is restricted to the FLP.

More difficult to grasp are the effects on the second, third and fourth moments of the loss rate distribution. First, consider the standard deviation. In Table 2 the standard deviation of the new portfolio exceeds that of the original portfolio. Intuitively, this is explained by scaling up losses through securitization and reinvestment. But this is not true in general. Let the par value of the original portfolio be $1 \$$. If the bank securitizes this portfolio taking a FLP of $0.1 \$$, it grants new loans for $0.9 \$$. Let $\sigma_{o p}$ denote the standard deviation of the loss of the original portfolio, $\sigma_{f l p}$ the standard 
deviation of the loss on the FLP, and $\rho$ the correlation coefficient between losses. Then the variance of the new portfolio equals

$$
\sigma_{f l p}^{2}+2 \cdot 1 \cdot 0.9 \cdot \rho \cdot \sigma_{o p} \cdot \sigma_{f l p}+0.9^{2} \cdot \sigma_{o p}^{2}
$$

while the variance of the original portfolio equals $\sigma_{o p}^{2}$. Obviously, the variance of the new portfolio is smaller than that of the original portfolio if the FLP is small relative to expected loss so that it will be exhausted by losses with high probability. In the limit, $\sigma_{f l p}$ tends to zero, implying the variance of the new portfolio roughly to equal $81 \%$ of the variance of the original portfolio. Therefore it is not obvious whether the bank's standard deviation of default losses will increase or decline through securitization and reinvestment.

In Table 2, skewness and kurtosis of the new portfolio decrease relative to the original portfolio. From Figure 2, this is not surprising given a shift of the probability mass from the lower tail to the center. This effect is more dramatic for the kurtosis than for the skewness since the kurtosis raises the differences to the mean to the fourth instead of the third power.

Figure 2 about here

These effects can also be seen by looking at the cumulative loss distributions in Figure 3. These distributions show that the change in the loss rate distribution caused by securitization and reinvestment is not merely a shift, but also a spreading out of the distribution.

Figure 3 about here

Second, we look at the effects of correlations on these results. Of course, correlations have no effect on the average default rate of the original portfolio. This is always the same (around 5,67\%) even though the simulation produces slight differences. Figure 4 displays the difference between two frequency distributions of default losses of the original portfolio, the first being determined by correlations $(0.7 ; 0.3)$, the second by $(0.3 ; 0.0)$, with the first number being the intraindustry correlation and the second the interindustry correlation. Raising the correlations shifts probability mass from the range ( $6-24 \%$ ) to both tails. Therefore, the standard deviation, the skewness and the kurtosis of the default rate of the original portfolio increase with correlations.

Figure 4 about here

More complex is the effect of correlations on the default rate distribution of the new portfolio. Figure 4 indicates that a FLP of about 10 percent has to bear small losses (1-5\%) with higher probabilities, and high losses (6-10\%) with lower probabilities. Hence, in this example, higher correlations imply a 
lower average loss for the FLP. This also explains in Table 2 why the ratio of average losses of the new over the original portfolio declines with higher correlations.

Table 2 also indicates for our example that standard deviation and skewness of the new portfolio increase with correlations, while this is not always true of the kurtosis. The relative increase in standard deviation (new over original portfolio) tends to slightly decline with higher correlations. The relative changes in skewness and kurtosis do not display such regular patterns.

The simulation exercise begs the question whether securitization and reinvestment will have an impact on the systematic risk of the bank measured by the sensitivity of the bank's default losses to a macrofactor of default losses. If the bank retains the first loss piece and reinvests the proceeds from securitization in loans to new obligors, then tranching and reinvestment raise the granularity of the total loan book, which in turn raises the bank's systematic cash flow risk. As a result, the bank's stock market beta might be affected as well. We will look into this matter in the next section.

\section{Share price reactions to the issue of Collat- eralized Debt Obligations}

In this section we want to analyze how the securitization of loan assets affects the equity valuation of the bank. In accordance with the last section, emphasis will be on effects that are due to tranching and reinvestment. Earlier studies, including the event studies [22] and [30], have neglected the important risk repackaging aspect of loan securitization.

\subsection{Hypotheses and test design}

Our main hypothesis relates the effects of securitization to the systematic stock market risk of the bank measured by its beta. The change in beta depends on the change in the standard deviation of the bank's stock return and the change in the correlation between the bank's stock return and the market return. In order to derive hypotheses about these changes, we assume, first, that a higher standard deviation of the default losses incurred by the bank translates into a higher standard deviation of its stock return. Second, we assume that an increase in the granularity of the bank's loan portfolio translates into a higher correlation between the bank's stock return and the market return. This is motivated by the empirical observation that the credit 
spread of a corporate bond is negatively related to the corporation's stock return (see, for example, [3] and [6]). Hence the market value of a loan portfolio should be positively correlated with the market value of a portfolio of the stocks of the underlying corporations which, in turn, are positively correlated with the market return. The more granular the loan portfolio, the better diversified it will be, and the stronger should be the correlation of its market value with the market return. Given the immediate impact of the market value of the bank's loan portfolio on its own market value, a more granular loan portfolio should translate into a higher correlation between the bank's stock return and the market return.

In the following we consider a bank which in a securitization retains the first loss piece and sells or swaps the other tranches to investors. As shown before, the securitization impact on the bank's risk depends strongly on the bank's reinvestment policy. We consider again the two polar cases discussed before.

If the bank securitizes the loan portfolio in a true sale transaction, but takes no new risks, then the standard deviation of the bank's default losses should decline because the bad tail risks of the loss distribution are transferred to investors. This is likely to reduce the standard deviation of the bank's stock return, holding the liability side of its balance sheet constant. Similarly, if the bank repays some of its debt, holding the equity capital constant, then this should also reduce the standard deviation of the bank's stock return. Regarding the correlation between the bank's stock return and the market return, we expect a slight decline because the transfer of the bad tail risks to investors immunizes the bank to very bad outcomes of macro factors. Hence, overall we expect a slight decline of the bank's beta after a securitization given a risk-free reinvestment policy.

Now consider the other polar case in which the bank reinvests the proceeds from securitization in new loans of comparable quality. As shown before, the standard deviation of the bank's default losses is likely to increase which should also raise the standard deviation of the bank's stock return. Since the reinvestment raises the granularity of the bank's loan portfolio, this should raise the correlation between the bank's stock return and the market return. Therefore, given this reinvestment policy, the bank's beta should increase. This effect should be stronger for banks that engage in repeated securitizations and, thus, over time, increase the share of equity tranches among its assets. This motivates our first hypothesis.

Hypothesis 1 CDO-transactions will raise (reduce) the bank's beta if the proceeds of the securitization are reinvested in new loans to new obligors (risk-free assets). The effect will be stronger for repeated CDO-transactions. 
Hypothesis 1 addresses the two polar cases. Banks may well choose policies in between. Since we do not have detailed data on the banks' behavior, we cannot find out what the banks actually do. We can only try to find out whether the banks' betas increase or not. This is, at best, indirect evidence of the banks' policies. A more rigorous test would use figures from the quarterly reports of banks. Even using such figures it would be difficult to separate investment and capital structure decisions associated with securitizations from other decisions.

Similarly, one might argue that we should look at the banks' unlevered betas, i.e. the beta defined by the joint stock and bond return of the bank and that of the market. This would require daily data on the bank's debt a large part of which is not securitized. Since we do not have these data, we look at conventional betas. Given the small size of issues, $1.3 \%$ of the balance sheet on average (see Table 3), the relative effects on equity beta and on asset beta are likely to be quite similar.

Hypothesis 1 refers to beta changes at the time securitizations are announced, presuming that such announcements are a surprise. In some countries, especially the United States, some banks engage in securitization programs. Although the timing of individual securitizations in a program may not be perfectly anticipated by the market, the long-run effects on bank cash flows may be anticipated rather well, in which case we would expect little effect of announcements of individual securitizations. But at least during our sample period, European banks did not announce programs apart from mortgage-backed master trust securitizations, which are absent from our data. Thus, the number, size and timing of securitizations by European banks are difficult to predict. To the extent the market is nevertheless able to make predictions, it would tend to weaken our ability to find any impact of securitization on returns and betas.

We now turn to the stock price reaction triggered by the announcement of the securitization, as captured by the abnormal return in a typical event study. The abnormal return is determined by the expectation of investors, given the information contained in the issue announcement ${ }^{9}$. If stockholders interpret the securitization as a pure change in the bank's financing strategy, then in a perfect market there should be no stock price effect unless the change in the financing strategy redistributes wealth from the stockholders to the bondholders, or vice versa. Since the stockholders hold the equity piece and the bondholders hold the senior tranche of the bank's assets, securitization without risky reinvestment should typically reduce the expected default losses of the bank's bondholders and, thus, enrich them at the expense of the stockholders. This would argue in favor of a negative stock price reaction. Securitization with risky reinvestment might have the opposite effect. 
Similarly, if the bank uses a true sale transaction to obtain new funding, then stockholders may interpret the transaction as unfavorable information about the bank's funding needs and react by a stock price decline. This, however, would not be true for a synthetic transaction because then the bank does not receive funding. Finally, the transaction cost of securitization is nonnegligible, adding to a negative stock price impact.

On the other side, securitization enables the bank to expand its loan or other business. This may be considered by the stockholders as a valuable real option of the bank so that the stock price should increase. Similarly, to the extent that securitization protects the bank against major default losses, it may reduce the costs of financial distress. This would also be good news for the stockholders.

Summarizing, the net impact of securitization on the bank's stock price is hard to predict. It is an empirical matter as to which effects dominate. Across the entire sample, we do not expect to find significant stock price reactions to the announcement of securitizations.

We will provide evidence, first, by looking at all transactions, and second, by looking at different subsets of transactions to find out whether the hypothesis holds equally well for all these subsets.

There are a number of characteristics that may be relevant cross-sectionally. Among these characteristics is the synthetic nature of a deal, because synthetic deals eliminate the funding component in an issue and, therefore, synthetic issues should have a smaller impact on the bank's asset composition, relative to a fully funded transaction.

A second characteristic of securitization transactions that may be relevant for cross sectional differences is the nature of the issue as static or dynamic. Static issues maintain the original asset composition of the collateral portfolio throughout the life of the transaction. This typically implies a gradual redemption of the outstanding issue, in accordance with repayment of the underlying loans. Dynamic issues, in contrast, tend to maintain their original volume throughout the entire term of the issue. If loans in the collateral portfolio are redeemed, the issuer replaces them by new loans, safeguarding certain quality standards. While replenishment standards vary between issues, a general implication is that banks are required to assign new loans to the collateral portfolio in a systematic, non-random way.

Since both properties - synthetic/true-sale and static/dynamic- exert an influence on the asset composition of the bank, we expect both characteristics to be consequential for the value effect of the issue announcement. 


\subsection{Data and results of the event study}

In compiling our data set we initially looked at all transactions in Moody's European Securitization list of June 2003. The number of issues is 254, of which 185 have a Moody's "New Issue Report". It is this New Issue Report that contains the information required for conducting the study, including a description of the underlying assets as well as the covenants relevant for the issue. Among the many other features of the issue, the Report also contains the pricing of the tranches at the issue date and the name of the originator. Not every issue has a single originator ${ }^{10}$.

For 112 transactions we were able to identify the originator. We imposed the additional restriction that the originator is a listed company (else no stock price is available), and arrive at a sample of 92 transactions from 31 banks. We excluded the non-European banks and finally have 73 transactions issued by 27 banks. These issues are used for the event study and, later on, for the cross sectional analysis.

Table 3 presents the descriptives of our final data set. In the upper panel of Table 3 one can see that the average size of transactions is small relative to the entire balance sheet, up to $2 \%$ of total assets. For repeat issuers this share of balance sheet assets adds up to 5-10\% of total assets, and in some cases an even larger share of the total loan book. The average number of tranches over all transactions is about 6 . The lower panel refers to a subsample of the 73 issues, comprising 51 issues. It excludes repeat issues, i.e. all transactions whose issue date is less than 5 months (100 days) after another issue by the same bank. This subsample will also be used later in the regression analysis. The basic model is an augmented event study estimation.

$$
\begin{aligned}
& R_{i, t}=\alpha_{i}+\beta_{i} R_{m, t}+\gamma_{1, i} D_{i}^{\text {event }}+\gamma_{2, i} D_{i}^{\text {other event }}+\beta_{i}^{\Delta} D_{i}^{a f t e r} R_{m, t}+\varepsilon_{i, t} \quad ; \\
t= & -20, \ldots,+20
\end{aligned}
$$

The dependent variable $R_{i, t}$ as well as the independent variable $R_{m, t}$, are daily log returns, the latter being defined as the DJ EuroSTOXX index ${ }^{11}$. The dummy $D^{\text {event }}$ captures the abnormal return over the event window. The window extends from day -20 to day +20 around the announcement date. Announcement dates were assumed to be the first public notification that could be identified in Lexis-Nexis, or in pre-sale reports of the three major agencies.

The estimation uses a 200-days window, symmetrically around the event window. Thus, for each event the time series extends over 240 trading days, approximately one year. Since we are interested in a possible change of systematic risk, the regression has a second variable capturing systematic 
risk, delta-beta $\left(\beta^{\Delta}\right)$, which is multiplied by a dummy, $D^{\text {after }}$, which equals one for the 100 days following the event window $(-20,+20)$. The coefficient $\beta^{\Delta}$ measures the extent to which the after-event beta diverges from its preevent value. The null hypothesis sets $\beta^{\Delta}$ at zero.

The estimation is complicated by the fact that for many cases in our sample, there are repeat issuers, and the interval between two consecutive announcement dates by the same issuer frequently is less than 100 days. Since a separate regression is run for every transaction, there is overlap among the estimation windows. In order to disentangle the effect of the original event from the effects of other events, we include a dummy "other event", $D^{\text {other event }}$, whose coefficient captures abnormal returns in a $-20 /+20$ days window around each other event.

To deal with $\beta^{\Delta}$ in these frequent issue-cases, we set the dummy $D^{\text {after }}$ equal to two (three) for the second (third) subsequent overlapping event. Thus, we force $\beta^{\Delta}$ to be of the same order of magnitude for all successive and overlapping events.

In order to account for contemporaneous correlations between the regressors, we employ the Seemingly Unrelated Regression (SUR) methodology. Contemporaneous correlation between regressors is to be expected, since we observe some clustering of the event dates (see Figure 5). The regression system is run in calendar time rather than in event time, so that contemporaneous correlations are properly accounted for ${ }^{12}$. To check the robustness of our results, the regressions were also run in event time, and as OLS regressions. All estimations yield qualitatively the same results.

Figure 5 and Table 4 about here

The regression results are presented in table 4 . While regression A.1 covers all 73 events, regression A.2 uses only the 51 events without overlap. Clearly, the announcement of a securitization does not generate abnormal stock returns. In regression A.1 the average values of the coefficients $\bar{\gamma}_{1}$ and $\bar{\gamma}_{2}$ are very close to zero and insignificant. In regression A.2, $\bar{\gamma}_{1}$ is higher, but still insignificant. Thus, our conjecture that the announcement of securitizations does not yield significant abnormal returns is confirmed.

Securitization has, however, a rather impressive effect on the banks' average beta. Even though the the relative increase in beta is rather modest, this is to be expected, given the small size of most securitizations relative to bank size. In regression A.1, beta increases in the post-securitization period by 0.05 , as shown by the coefficient of $\beta^{\Delta}$. The coefficient is highly significant. This finding suggests that many banks engaged in securitizations increase their exposure vis-à-vis the market return. Our data, however, do 
not allow us to infer the sources of this increase in systematic risk.

In regression A. 2 we look at the subsample of securitization events without overlap. Now the coefficient of $\beta^{\Delta}$ turns out to be much lower, also the significance level is much lower. This sample underrepresents repeat issuers, i.e. the large issuers. Thus, the beta increase after securitizations is much stronger for repeat issuers. These are more likely to systematically increase their risk after securitization.

The surprisingly strong increase in beta raises the question whether this finding may be biased. In particular, it is possible that the beta of the banking industry increased over the sampling period and this effect accounted for the observed securitization impact on beta. In order to check for this possibility, we also estimated an augmented model

$$
\begin{aligned}
& R_{i, t}=\alpha_{i}+\beta_{i} R_{m, t}+\gamma_{1, i} D_{i}^{\text {event }}+\gamma_{2, i} D_{i}^{\text {other event }} \\
& +\beta_{i}^{\Delta} D_{i}^{a f t e r} R_{m, t}+\delta_{i}\left(R_{b, t}-R_{m, t}\right)+\delta_{i}^{\Delta} D_{i}^{a f t e r}\left(R_{b, t}-R_{m, t}\right)+\varepsilon_{i, t} \\
& t=-20, \ldots,+20 .
\end{aligned}
$$

This regression includes as an additional regressor the excess bank index return $R_{b}-R_{m}$, defined as the log return of the European bank stock index minus the log market return.

In the augmented model, as shown in regression A.3 in table 4, the sensitivity of the single bank stock return with respect to the market return over the whole event window, the traditional beta, is now 0.82 , while it is 0.68 for the excess bank index return ${ }^{13}$. Looking at the changes of these sensitivities after securitization, the traditional beta increases by a significant 0.062 , essentially unchanged from regression A.1, while the sensitivity with respect to the excess bank index return increases by 0.14 , which is highly significant. Hence, taking both increases together, they are even more impressive than in in the one index model A.1. This indicates again, that on average the banks engaging in securitizations expand their risk taking ${ }^{14}$. Therefore, the increase in the traditional beta shown in regression A.1 does not appear to be driven by changes in the beta of the bank index return.

Given the increase of the traditional beta after securitization (regression A.1), we next ask whether this increase differs across types of transactions. For that purpose, we regress the bank specific increases of $\beta_{i}^{\Delta}$, as estimated in regression A.1, on a set of transaction-specific characteristics. The estimated model is:

$$
\begin{aligned}
& \beta_{i}^{\Delta}=\alpha+\lambda_{1} D_{i}^{\text {dynamic }}+\lambda_{2} D_{i}^{\text {synthetic }}+\lambda_{3} D_{i}^{C L O}+\lambda_{4} D_{i}^{C B O}+\lambda_{5} D_{i}^{\text {other }}+ \\
& \lambda_{6-8} D_{i}^{\text {year }}+\varepsilon_{i}
\end{aligned}
$$

The explanatory variables generate partitions of the sample. In par- 
ticular, $D^{\text {dynamic }}$ is a dummy variable that equals one for managed issues, i.e. collateral portfolios that are being replenished over the life of the issue. $D^{\text {synthetic }}$ separates between synthetic and fully funded true sale issues, where the dummy equals one for synthetic issues. $D^{C L O}, D^{C B O}$, and $D^{\text {other }}$ subdivides the sample into four categories according to the type of the underlying asset portfolio, as loans, bonds, mortgages (the reference group), and all others (e.g. credit card or leasing claims). The $D^{\text {year }}$-dummies stands for the issue years, with 2002 as the reference year.

The cross section analysis of $\beta^{\Delta}$ reported in Table 5 offers additional insight in what drives the increase in beta after securitizations. Among the structural characteristics, the dummy for managed issues, $\lambda_{1}$, is the only one that turns out significant. Since its sign is negative, it signifies that managed issues have a lower increase in systematic risk, i.e. the bank may be less motivated to increase granularity in the aftermath of a securitization, or the bank may be more concerned to restrict the new risks to avoid early termination of the transaction, relative to static deals. The variables representing the type of underlying asset, like CLOs, CBOs remain insignificant altogether.

Clearly, these findings are explorative in nature, and they will have to be followed up by an integration of structural data concerning the collateral assets as well as balance sheet details of the bank.

\section{Conclusions}

In this paper we have analyzed the design of CDO transactions and its impact on the default risk exposure of the originating bank. These risk effects are measured in two different ways, the impact on the bank's default losses and on its stock beta. The latter reflects the impact on the systematic risk in the stock market. Adverse selection and moral hazard problems which are considered strong barriers to trading default risks, are largely eliminated in a CDO-transaction by a substantial first loss position of the originator. The size of this position increases with the average default probability of the underlying portfolio. Typically, only a small portion of default losses of the underlying portfolio is transferred in a CDO-transaction. In addition to the first loss piece, tranching typically leads to a large senior tranche which in the case of a fully funded transaction may be sold to investors so that the originator is protected against high default losses that otherwise might lead to financial distress.

The bank can adjust its policy to securitization in different ways. In one polar case it does not take new risks, in the other polar case it strongly 
expands its risk taking. The impact of securitization and reinvestment on the banks' default risk is illustrated in a simulation exercise which also illustrates the impact of default correlations on the bank's risk exposure. If the bank uses the securitization proceeds to expand its loan business, then its default risk tends to increase. This tends to translate also into an increase in its stock beta. On average, a beta increase is confirmed by our empirical findings. Our evidence suggests that many banks use the risk reduction achieved through securitization to take new risks. However, this finding has to be interpreted with care, given the size of the data set and the length of the observation period.

Finally, we tentatively draw some conclusions about consequences of securitizations for financial markets. The risk transfer achieved by securitization depends as much on the way the issue is tranched as on the allocation of these tranches to different groups of investors. The tranching technique allows to largely separate idiosyncratic risks from macro default risks. Assuming that the default risk of corporate loans depends on the relationship between the bank and its customers, tranching allows to allocate information-sensitive risks predominantly to the first loss piece, and to a lesser extent to the mezzanine pieces, while the large senior tranches are largely free of these risks. In turn, extreme macro risks are borne predominantly by the senior tranches. The return on these tranches is effectively indexed to systemwide economic shocks. To the extent that loan securitizations replace the traditional "riskfree" deposit-financing of banks, one may conclude that both, bank lending and funding are indexed to macro risks making the banks less vulnerable.

To what extent these effects exist, depends upon the allocation of tranches to different types of investors. To realize an optimal risk sharing, the first loss piece should be retained by the originating bank because then its incentives as a lender are kept intact. In contrast, senior tranches should be allocated to remote investors in order to improve stability of financial markets. Remote investors are defined as investors who are in a better position to withstand macro shocks so that their solvency is not endangered. In contrast, highly levered financial intermediaries without any hedge against macro shocks would be endangered and the domino effects of insolvencies might destabilize the financial system. Figures published by banks and bank regulators indicate that financial intermediaries themselves buy the bulk of CDO-tranches. It appears that originating banks often retain the non-securitized senior portion in synthetic deals. This indicates that the banking system as a whole is not effectively hedged against macro shocks. Financial stability would be improved if banks would neither invest in the senior tranches nor retain them, but sell them to more remote investors.

These tentative conclusions suggest a demand for more research along the 
lines we have presented in this paper. On the modelling side, the correlation structure between tranches of different seniority is relevant for CDO-bond portfolio management and for assessing financial system stability. For example, a change in the correlation between asset classes not only alters the default probabilities of tranches, but also the joint default probabilities of different tranches. The latter statistic is relevant for the analysis of contagion effects, as pointed out by [17] and [2]. On the empirical side, more research is needed to find out how banks change their business policy in response to securitization. In addition, more evidence is required on the effective allocation of tranches to investor groups, and on the expanded role of commercial banks as intermediaries between capital markets and the corporate sector, as discussed in [18]. It appears that the securitization of bank loans provides an efficient new tool to combine the advantages of bank- and market-based financial systems.

\section{References}

[1] Arrow, K. (1971). Essays in the theory of risk bearing, Markham.

[2] Bae, K.-H., Karolyi, G. A., R. M. Stulz (2003). A new approach to measuring financial contagion, Review of Financial Studies 16, 717-764.

[3] Blanco, R., Brennan, S., and I.W. Marsh (2003). An empirical analysis of the dynamic relationship between investment-grade bonds and credit default swaps. Working paper no. 211, Bank of England.

[4] Calomiris, C. W. and J. R. Mason (2004). Credit card securitization and regulatory arbitrage, Journal of Financial Services Research 26, 5-27

[5] Cebenoyan, A.S. and P.E. Strahan (2004). Risk management, capital structure and lending at banks, Journal of Banking and Finance 28, $19-43$.

[6] Collin-Dufresne, P., Goldstein, R.S. and J.S. Martin (2001). The determinants of credit spread changes, Journal of Finance 56, 2177-2207.

[7] Das, S. (2000). Credit derivatives and credit linked notes, 2nd edition, John Wiley.

[8] DeMarzo, P. (2005). The pooling and tranching of securities: a model of informed intermediation, Review of Financial Studies 18, 1-35. 
[9] Deutsche Bundesbank (2004). Instrumente zum Kreditrisikotransfer: Einsatz bei deutschen Banken und Aspekte der Finanzmarktstabilität, Monatsberichte April, 27-45.

[10] Deutsche Bank Research (2004),. European Securitisation: 2003 Review \& Outlook 2004, January.

[11] Diamond, D.W. and R.W. Rajan (2001). Liquidity risk, liquidity creation, and financial fragility: a theory of banking, Journal of Political Economy 109, 287-327.

[12] Elsas, Ralf und J.P. Krahnen (2004). Universal banks and relationships with firms, German Financial System, Oxford University Press (Eds. Krahnen, J.P. and R.H. Schmidt), 197-232.

[13] Fabozzi, F.J., Modigliani, F., Jones, F.J. and M.G. Ferri (2002). Foundations of Financial Markets and Institutions, 3rd ed., Prentice Hall.

[14] Fitch Rating (2004). CDO Squared: A Closer Look at Correlation, London, FitchRatings, February 2.

[15] Franke, G. and J. P. Krahnen (2004). Understanding CLO markets, working paper, preliminary draft October.

[16] Gale, Douglas and Martin Hellwig (1985). Incentive-compatible debt contracts: The one-period problem, Review of Economic Studies 52, 647-663.

[17] Gersbach, Hans (2002), "Financial Intermediation and the Creation of Macroeconomic Risks", CESifo Working Paper Series No. 695, April.

[18] Gorton, Gary und George G. Pennacchi (1995). Banking and loan sales: marketing non-marketable assets, Journal of Monetary Economics 35, $389-411$.

[19] Greenbaum, Stuart, and Thakor, Anjan (1987). Bank funding models: securitization versus deposits, Journal of Banking and Finance 11, 379401.

[20] Hellwig, Martin (1994). Liquidity provision, banking, and the allocation of interest rate risk, European Economic Review 38, 1363-1389.

[21] Hellwig, Martin (1998), Banks, markets, and the allocation of risks in an economy, Journal of Institutional and Theoretical Economics 154, $328-345$. 
[22] Lockwood, Larry J., Rutherford, Ronald C., Herrera, Martin J. (1996). Wealth effects of asset securitization, Journal of Banking and Finance 20, 151-164.

[23] Longin, F. M., B. Solnik (2001). Extreme correlations of international equity markets during extremely volatile periods, Journal of Finance $56,649-676$.

[24] Miller, Geoffrey P. (1998), On the Obsolescence of Commercial Banking, Journal of Institutional and Theoretical Economics 154, 61-77.

[25] Moody's Investor Service (2002), Default and Recovery Rates of European Corporate Bond Issuers, 1985-2001, July.

[26] Ongena, S., und D.C. Smith (2000). 'Bank relationships: A review.' The performance of financial institutions, eds. P. Harker and A. Zenios. Cambridge University Press.

[27] Plantin, Guillaume (2003). Tranching, London School of Economics working paper, April..

[28] Riddiough, T. (1997). Optimal design of asset backed securities, Journal of Financial Intermediation 6, 121-152.

[29] Standard \& Poors (2002). Global cash flow and synthetic CDO criteria, Standard \& Poors Structured Research, March 21.

[30] Thomas, Hugh (2001). Effects of asset securitization on seller claimants, Journal of Financial Intermediation 10, 306-330..

[31] Townsend, Robert M. (1979). Optimal contracts and competitive markets with costly state verification, Journal of Economic Theory 21, 265293. 


\section{Notes}

${ }^{1}$ In addition to the persons mentionned already, we thank Andreas Jobst for helping us to set up the data base and to discuss the intricacies of ABS markets, and Ralf Elsas for helpful comments. We are also indebted to market experts from major banks and agencies for their support and comments, in particular M. Hermann (HSBC), T.Weinelt (Commerbank), S. Nicolaus and R. Froitzheim (Deutsche Bank), T. Althaus (S\&P), S. Bund (Fitch), C. Benkert (JPMorgan), T. Klotz (Moody's), J. Wasmund (DWS), C.-R. Wagenknecht and B. Specht (DrKW) . Furthermore, we have received numerous helpful suggestions during the 2004 NBER-conference on Risks in Financial Institutions in Woodstock, Vermont. We are particularly indebted to our discussant, Patricia Jackson, and to Gary Gorton, Phillipe Jorion, Hashem Pesaran and Til Schuermann for their valuable comments and suggestions.

${ }^{2}$ The strict seniority can be weakened by early amortization provisions. If, for example, a AAA-Tranche and a A-tranche get repaid annually, then the latter tranche may receive substantial repayments in the early years, which, in the end, may reduce the final repayments on the AAA-tranche.

${ }^{3}$ See [26] and [12] for a review of relationship lending and its role in a bank-oriented financial system.

${ }^{4}$ Offering Circulars (OC) are official documents describing the issue's collateral composition, among many other contractual and legal details of the arrangement. OCs are public information to be posted at the issue date. In addition, most issues are accompanied by pre-sale reports published by rating agencies.

${ }^{5}$ There are a few simplifying assumptions: (i) there is no rating upgrade once an asset has reached default status; (ii) a defaulted asset returns the recovery rate multiplied by the nominal amount immediately; (iii) every asset has a bullet structure, there is no prepayment.

${ }^{6}$ The size of the senior tranche reported in the last line of Table 1 may therefore differ somewhat from the value reported in the offering circulars. However, this method allows us to estimate the loss quantiles allocated to tranches, an information not available in the offering circulars.

${ }^{7}$ All issues were selected for which we could get the offering circular. 
${ }^{8}$ The size of the first loss piece is measured in percent of the underlying portfolio volume.

${ }^{9}$ From conversation with practitioners we know that the valuation of CDO mezzanine tranches is typically preceded by a bookbuilding period resembling an English auction, as modeled in [27].

${ }^{10}$ Several ABS products are managed arbitrage deals that pass through the cash flows of several originators at once.

${ }^{11}$ We also ran the regressions with excess returns, rather than returns, and found the same results.

${ }^{12}$ With $73 \times 241$ observations, there are enough degrees of freedom to estimate all coefficients in the SUR system. The regressions were also run in event time, without having a material effect. In fact, the results are very close, even numerically.

${ }^{13}$ Thus the market sensitivity increases from 0.74 (in regression A.1) to 0.82 (in A.3), due to the addition of the excess bank return index. The net sensitivity w.r.t. the market is 0.14 , while it is 0.68 for the excess bank index.

${ }^{14}$ We also employed alternative specifications of the banking industry model, using $R_{b}$ as a regressor, rather than the difference of $\left(R_{b}-R_{m}\right)$, and using the error term from a first stage regression that relates $R_{b}$ to $R_{m}$. All specifications lead to the same qualitative results. Furthermore, we also ran the regression in event time, and as a set of OLS-regressions, with very similar results for all specifications. 
Figure 1: Loss distribution of London Wall 2002-2, 50'000 iterations

This table displays the loss distribution of London Wall, as it was simulated using the information contained in the Offering Circular. A loss rate distribution for the entire portfolio is generated that takes into account the correlation within and between industries and the credit migration risks referencing Standard and Poor's tables. The chart shows on the vertical axis the frequency of observations, and on the horizontal axis the associated loss rate, truncated at $13 \%$. There was no observation surpassing this threshold.

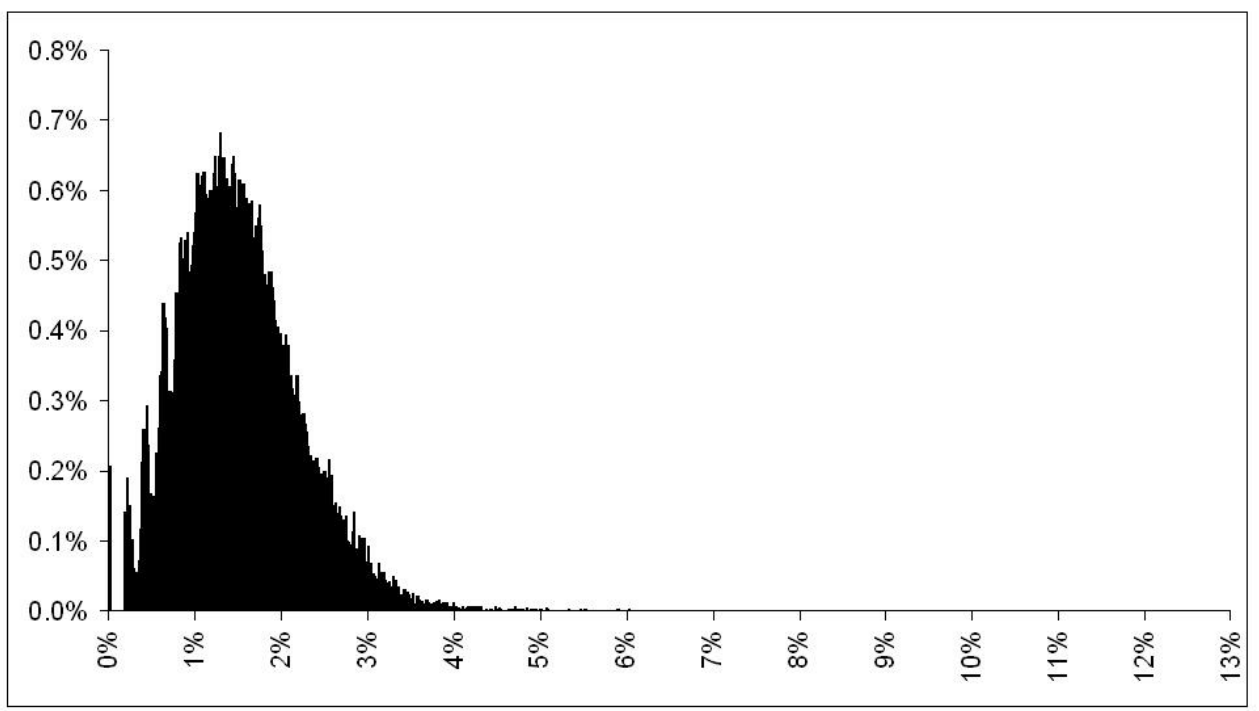


Figure 2: Securitization and reinvestment: Impact on marginal loss distribution, 10'000 iterations

This table displays the differential loss rate distribution of a simulated loan portfolio with securitization followed by reinvestment, and without reinvestment. The original portfolio consists of 50 B-rated loans of equal par value with one year to maturity, split evenly across five industries. The new portfolio is obtained by securitizing the original portfolio retaining a first loss piece of 10.11 percent and reinvesting the par value of the original position minus the first loss piece in another portfolio which has the same characteristics. The loss given default is assumed to be 52.5 percent. The pairwise within-industry correlations are 0.3, while pairwise between-industry correlations are assumed to equal 0.0. The resulting differential loss rate distribution is displayed in the figure.

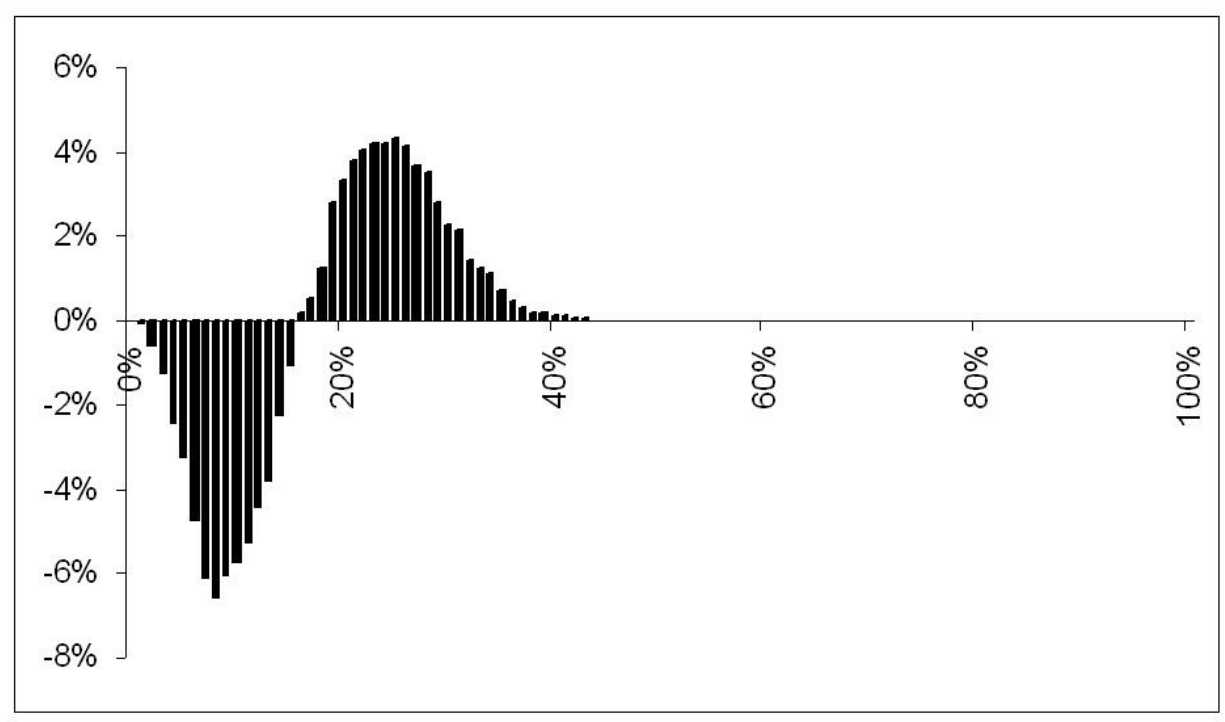


Figure 3: Securitization and reinvestment: Impact on cumulative loss distribution, 10'000 iterations

This table displays the cumulative loss rate distributions of a simulated loan portfolio with securitization and reinvestment (new), and without reinvestment (original). The same data as in Figure 2 are used.

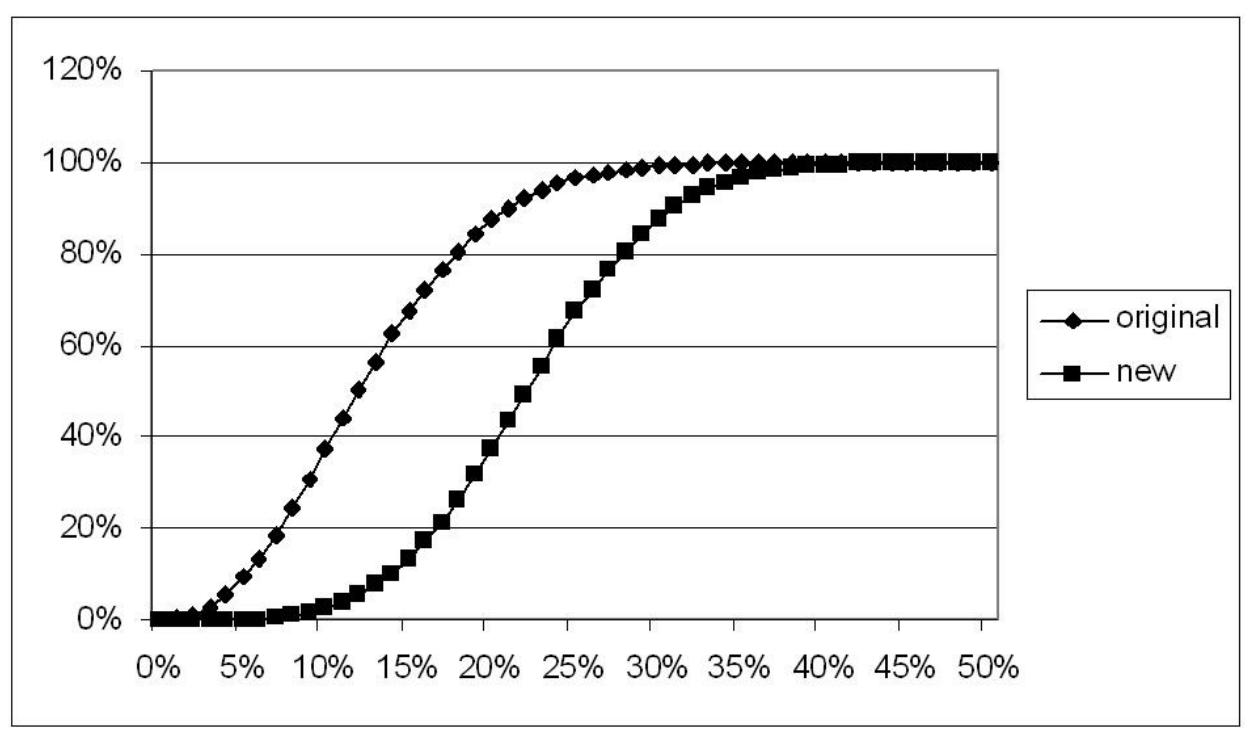


Figure 4: Increase in correlation and marginal loss distribution, 10'000 iterations

This table displays the differential loss rate distribution of a simulated loan portfolio with a low and a high level of correlation. In the underlying collateral portfolios there are 100 assets each, all BB rated, 2 industries, the pairwise within-industry correlations increase from 0.3 to 0.7 , while pairwise betweenindustry correlations increase from 0.0 to 0.3 . The resulting differential loss rate distribution is displayed in the figure.

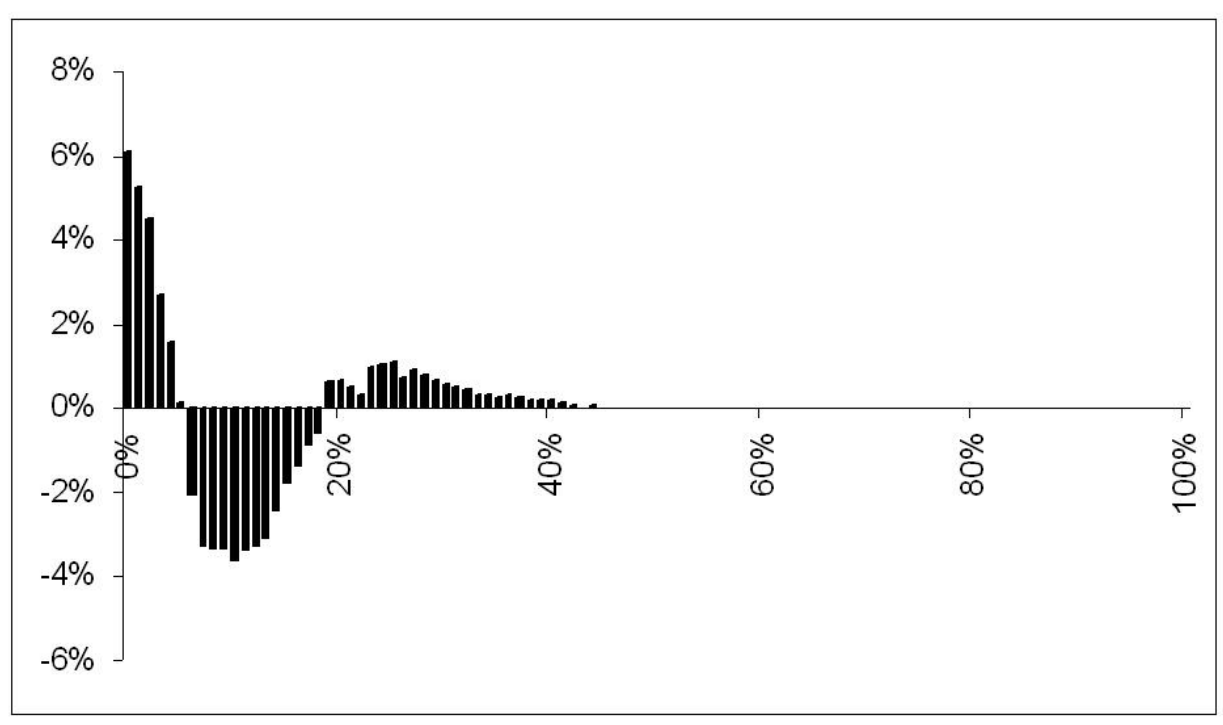


Figure 5: Time series of announcement dates

This figure plots the announcement of all 73 announcement dates between January 1999 and September 2002.

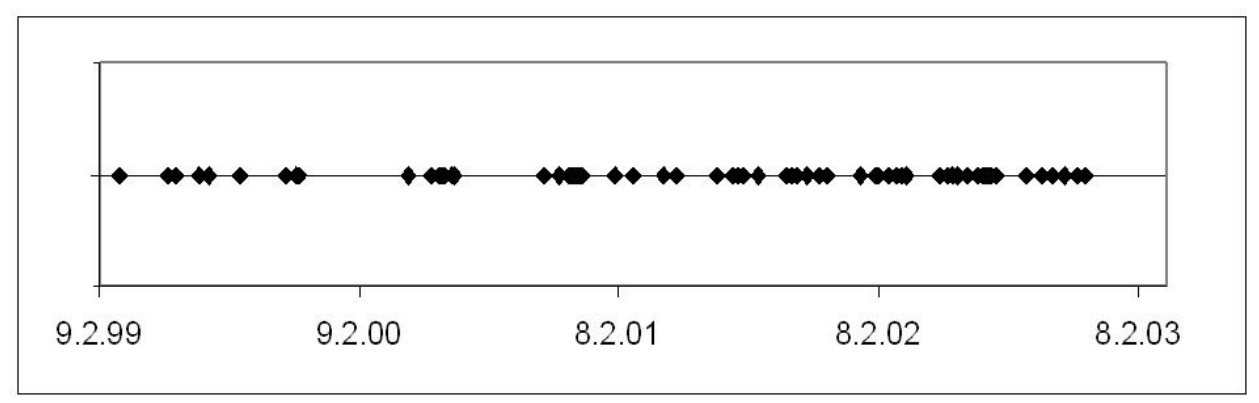


Table 1: Loss rate distribution of European CDOs: Descriptive Statistics

This table summarizes basic characteristics of the CDO sample with 40 European transactions used in the estimation of expected and unexpected loss. SME-CLOs are collateralized loan obligations where underlyings comprise loans to small and medium size firms, CBOs are collateralized bond obligations, with large firm corporate bonds as underlyings, and Non-SME-CLOs are a mixture of the two asset classes, comprising corporate bonds and loans to large firms. The numbers in the table are averages across the transactions listed in the column. Total volume is the amount in EUR of the portfolio underlying the transaction, the number of tranches is the number of issued tranches, excluding the FLP. Size FLP is the nominal value of a tranche relative to the nominal amount of the issue in fully funded and synthetic transactions, Size Senior Tranche is the nominal value of the senior tranche relative to the nominal amount of the issue, $\mathrm{FLP} / \mathrm{E}(\mathrm{L})$ is the size of the FLP tranche relative to expected loss $\mathrm{E}(\mathrm{L})$ of the underlying portfolio, and the FLP quantile is the cumulative density of losses not exceeding the size of the first loss piece. All tranche related statistics rely on our own estimation of the loss rate distribution.

\begin{tabular}{|c|c|c|c|}
\hline & $\begin{array}{c}\text { SME- } \\
\text { CLO }\end{array}$ & $\begin{array}{c}\text { Non-SME- } \\
\text { CLO }\end{array}$ & CBO \\
\hline Total volume (bn EUR) & 2.068 & 1.392 & 1.126 \\
\hline Number of claims & 2,303 & 153 & 100 \\
\hline Portfolio rating (median) & $\mathrm{Ba} 1$ & $\mathrm{Baa} 2$ & $\mathrm{Baa} 1$ \\
\hline $\begin{array}{c}\text { Most junior rated tranche } \\
\text { (median) }\end{array}$ & $\mathrm{Ba} 2$ & $\mathrm{Ba} 1$ & $\mathrm{~A} 3$ \\
\hline Size FLP (in \%) & 6.7 & 8.61 & 5.93 \\
\hline FLP/E(L) & 1.34 & 1.74 & 3.36 \\
\hline FLP quantile (cdf) & 0.87 & 0.87 & 0.96 \\
\hline Number of tranches & 4.57 & 4.17 & 2.85 \\
\hline Size Senior Tranche (in \%) & 91.11 & 87.79 & 92.89 \\
\hline
\end{tabular}


Table 2: Reinvestment of securitization proceeds: Simulation results for the loss rate distributions

This table summarizes the results of a simulation exercise. The original portfolio consists of 50 B-rated loans of equal par value with one year to maturity, split evenly across five industries. The new portfolio is obtained by securitizing the original portfolio retaining a first loss piece of 10.11 percent and reinvesting the par value of the original position minus the first loss piece in another portfolio which has the same characteristics. The loss given default is assumed to be 52.5 percent. There are three scenarios in the table, which differ by their correlation assumptions. The lower panel shows the first four moments of the resulting loss rate distribution for the bank's loan book, including the retained first loss tranches, for the three scenarios. The first column (original portfolio) describes the loan book before securitization, the second (new portfolio) describes the loan book after the securitization transaction.

\begin{tabular}{|c|c|c|c|c|c|c|}
\hline \multicolumn{7}{|c|}{ Panel I: Assumptions regarding correlations } \\
\hline $\begin{array}{c}\text { Within } \\
\text { industries }\end{array}$ & \multicolumn{2}{|c|}{0.3} & \multicolumn{2}{c|}{0.5} & \multicolumn{2}{c|}{0.7} \\
\hline $\begin{array}{c}\text { Between } \\
\text { industries }\end{array}$ & \multicolumn{2}{|c|}{0.0} & \multicolumn{2}{c|}{0.0} & \multicolumn{2}{c|}{0.3} \\
\hline \multicolumn{7}{|c|}{ Panel II: Moments } \\
\hline & $\begin{array}{c}\text { Original } \\
\text { portfolio }\end{array}$ & $\begin{array}{c}\text { New } \\
\text { portfolio }\end{array}$ & $\begin{array}{c}\text { Original } \\
\text { portfolio }\end{array}$ & $\begin{array}{c}\text { New } \\
\text { portfolio }\end{array}$ & $\begin{array}{c}\text { Original } \\
\text { portfolio }\end{array}$ & $\begin{array}{c}\text { New } \\
\text { portfolio }\end{array}$ \\
\hline Mean & $5.67 \%$ & $10.51 \%$ & $5.70 \%$ & $10.30 \%$ & $5.64 \%$ & $9.52 \%$ \\
\hline $\begin{array}{c}\text { Standard } \\
\text { deviation }\end{array}$ & $3.52 \%$ & $5.43 \%$ & $4.29 \%$ & $6.61 \%$ & $7.63 \%$ & $11.26 \%$ \\
\hline Skewness & 0.81 & 0.44 & 1.00 & 0.52 & 2.03 & 1.34 \\
\hline Kurtosis & 0.68 & -0.32 & 1.04 & -0.46 & 4.76 & 1.13 \\
\hline
\end{tabular}




\section{Table 3: European CDO data set: descriptive statistics}

This table presents descriptive statistics of the CDO data set. The numbers (except no. of issues) are averages across transactions. The upper Panel I uses information on 73 issues underlying the estimations in section 3, collected from Datastream. The lower Panel II represents a subsample of 51, comprising only those issues that did not experience a repeat issue by the same issuer within five months after the first transaction. 'Size' is the Euro volume of collateral assets underlying the issue, "Number of tranches" is taken from the offering circulars. All tranches, including non rated tranches, are considered. "Share of balance sheet assets" divides Size by total assets of the bank. "Equity (book value)" is the sum of equity and open reserves, according to Datastream.

\begin{tabular}{|c|c|c|c|c|c|}
\hline \multicolumn{6}{|c|}{ Panel I: European data set (n=73) } \\
\hline Year & $\begin{array}{c}\text { Number of } \\
\text { issues }\end{array}$ & $\begin{array}{c}\text { Size (collateral } \\
\text { assets, } € \text { bn) }\end{array}$ & $\begin{array}{c}\text { Number of } \\
\text { tranches }\end{array}$ & $\begin{array}{c}\text { Share of balance } \\
\text { sheet assets, in \% }\end{array}$ & $\begin{array}{c}\text { Equity (book } \\
\text { value, } € \text { bn) }\end{array}$ \\
\hline 1999 & 10 & 1.682 & 6.40 & 0.54 & 12.531 \\
\hline 2000 & 17 & 2.586 & 5.53 & 1.42 & 11.725 \\
\hline 2001 & 20 & 2.629 & 5.60 & 2.08 & 14.692 \\
\hline 2002 & 26 & 1.940 & 6.30 & 0.95 & 15.048 \\
\hline \multicolumn{7}{|c|}{ Panel II: Subsample of non-repeat issues (n=51) } \\
\hline Year & Number of & $\begin{array}{c}\text { Size (collateral } \\
\text { issues }\end{array}$ & $\begin{array}{c}\text { Number of } \\
\text { tranches }\end{array}$ & $\begin{array}{c}\text { Share of balance } \\
\text { sheet assets, in \% }\end{array}$ & $\begin{array}{c}\text { Equity (book } \\
\text { value, } € \text { bn) }\end{array}$ \\
\hline 1999 & 7 & 1.674 & 5.43 & 0.66 & 10.341 \\
\hline 2000 & 14 & 2.640 & 5.36 & 1.52 & 10.758 \\
\hline 2001 & 15 & 2.850 & 5.67 & 2.66 & 12.440 \\
\hline 2002 & 15 & 1.912 & 6.60 & 1.48 & 9.617 \\
\hline
\end{tabular}




\section{Table 4: Announcement effects: regression results}

This table reports the results of the event study relating to the announcement of CDO issues. A calendar time SUR estimation of the determinants of issue banks' excess stock returns was employed. The first and third regression (A.1 and A.3) are time series estimations with 73 events over a window of 241 trading days. The second regression (A.2) has 51 events, excluding overlapping events by the same issuer (i.e. repeat issues). All regressions use data from the period January 1999 to December 2002. The dependent variable in all regressions is $\mathrm{R}$ (it), the daily log return on 27 banks (from Datastream). The explanatory variables are $\mathrm{R}(\mathrm{mt}), \mathrm{R}(\mathrm{bt}), \mathrm{D}$ (event), $\mathrm{D}$ (other event) and $\mathrm{D}$ (after). $\mathrm{R}(\mathrm{mt})$ is the log return on the DJ EuroStoxx and $\mathrm{R}(\mathrm{bt})$ is the log return on the DJ Euro STOXX Bank. Both indices are taken from Datastream. D(event) equals one for the event window $[-20,+20]$, where the event is the announcement date of the CDO issue, $\mathrm{D}$ (other event) equals one for all other event windows in the period $[-120,+120]$, and $\mathrm{D}$ (after) equals one for the period $[+20,+120]$. If there is more than one other event, the dummy D-after is equal to two (three) for the second (third) subsequent overlapping event. Wald-statistics (p-values) are in parentheses.

$$
\begin{aligned}
& R_{i, t}=\alpha_{i}+\beta_{i} R_{m, t}+\gamma_{1, i} D^{\text {event }}+\gamma_{2, i} D^{\text {otherevent }} \\
& +\beta^{\Delta}{ }_{i} D^{\text {after }} R_{m, t}+\delta_{i}\left(R_{b, t}-R_{m, t}\right)+\delta_{i}^{\Delta} D^{\text {after }}\left(R_{b, t}-R_{m, t}\right)+\varepsilon_{i, t}
\end{aligned}
$$

\begin{tabular}{|c|c|c|c|c|c|c|c|}
\hline & $\bar{\alpha}$ & $\beta$ & $\overline{\gamma_{1}}$ & $\bar{\gamma}_{2}$ & $\overline{\beta^{\perp}}$ & $\bar{\delta}$ & $\bar{\delta}^{\Delta}$ \\
\hline $\begin{array}{l}\text { A.1 }(n=73) \\
\quad \text { w/ repeat issues }\end{array}$ & $\begin{array}{l}-0.0003 \\
(0.982)\end{array}$ & $\begin{array}{l}0.7413 \\
(0.000)\end{array}$ & $\begin{array}{l}-0.0003 \\
(0.360)\end{array}$ & $\begin{array}{l}0.0003 \\
(0.456)\end{array}$ & $\begin{array}{l}0.05097 \\
(0.003)\end{array}$ & -.- & $\ldots$ \\
\hline $\begin{array}{l}\text { A. } 2(\mathrm{n}=51) \\
\text { w/o repeat issues }\end{array}$ & $\begin{array}{l}-0.0003 \\
(0.943)\end{array}$ & $\begin{array}{c}0.6597 \\
(0.055)\end{array}$ & $\begin{array}{l}0.0165 \\
(0.343)\end{array}$ & $\cdots$ & $\begin{array}{l}0.00175 \\
(0.094)\end{array}$ & --- & --- \\
\hline $\begin{array}{l}\text { A. } 3(n=73) \\
\text { w/repeat issues }\end{array}$ & $\begin{array}{r}0.0002 \\
(0.894)\end{array}$ & $\begin{array}{l}0.8230 \\
(0.000)\end{array}$ & $\begin{array}{l}-0.004 \\
(0.289)\end{array}$ & $\begin{array}{c}0.003 \\
(0.773)\end{array}$ & $\begin{array}{l}0.062 \\
(0.021)\end{array}$ & $\begin{array}{l}0.684 \\
(0.000)\end{array}$ & $\begin{array}{c}0.137 \\
(0.007)\end{array}$ \\
\hline
\end{tabular}


Table 5: Announcement effects: second stage regression results

This table reports the results of the event study relating to the announcement of CDO issues. A SUR estimation of the determinants of excess stock returns of the issuing banks was employed. The regression in this table is a cross-sectional estimation of the determinants of delta-beta from the regression A.1 in Table 4, i.e. the change in systematic risk after an event. The explanatory variables are $\mathrm{D}(\mathrm{dyn}), \mathrm{D}(\mathrm{syn})$, $\mathrm{D}(\mathrm{CLO}), \mathrm{D}(\mathrm{CBO}), \mathrm{D}$ (other), D(99), D(00), D(01). D(dyn) equals one for a managed issue, D(syn) equals one for a synthetic issue. $\mathrm{D}(\mathrm{CLO}), \mathrm{D}(\mathrm{CBO})$ and $\mathrm{D}$ (other) equal one when the collateral portfolio consists of loans, bonds, or other assets. Mortgage backed securities are the reference group. D(99), D(00) and $\mathrm{D}(01)$ equal one for the issue year 1999, 2000 or 2001. p-values are in parentheses. As in Table 4, the estimation is with 73 events over a window of 241 trading days. The regression uses data from the period January 1999 to December 2002.

$$
\begin{array}{r}
\beta_{i}^{\Delta}=\alpha+\lambda_{1} \cdot D_{i}^{d y n}+\lambda_{2} \cdot D_{i}^{5 y n}+\lambda_{3} \cdot D_{i}^{C L O}+\lambda_{4} \cdot D_{i}^{C B O}+ \\
\lambda_{5} \cdot D_{i}^{\text {other }}+\lambda_{6} \cdot D_{i}^{99}+\lambda_{7} \cdot D_{i}^{00}+\lambda_{8} \cdot D_{i}^{01}+\varepsilon_{i}
\end{array}
$$

\begin{tabular}{ccccccccc}
$\alpha$ & $\lambda_{1}$ & $\lambda_{2}$ & $\lambda_{3}$ & $\lambda_{4}$ & $\lambda_{5}$ & $\lambda_{6}$ & $\lambda_{7}$ & $\lambda_{8}$ \\
\hline 0.061 & -0.165 & 0.129 & 0.006 & -0.111 & -0.057 & -0.282 & 0.172 & -0.017 \\
$(0.65)$ & $(0.02)$ & $(0.16)$ & $(0.95)$ & $(0.45)$ & $(0.62)$ & $(0.01)$ & $(0.04)$ & $(0.83)$
\end{tabular}

adj. $R^{2} \quad 0.235$ 
Table 6: List of European CDO issues used for loss rate estimation

This table summarizes descriptive statistics of the issues that have been used to calculate the loss rate distribution for the sample of European CDOs.

\begin{tabular}{|c|c|c|c|c|c|c|c|}
\hline Name & CBO/CLO & Maturity & $\begin{array}{l}\text { Volume } \\
\text { in } t r i f\end{array}$ & $\begin{array}{l}\text { Hrated } \\
\text { tranches }\end{array}$ & Hoare & $\begin{array}{l}\text { Rverage } \\
\text { Rating }\end{array}$ & $\begin{array}{l}\text { Div } \\
\text { Score }\end{array}$ \\
\hline Dutrh Care 2001-1 & CLO & 8 & 1300 & 3 & 169 & A1 & 12.4 \\
\hline Hesperic No. $1 \mathrm{pk}$ & CLO & 6 & 1.400 & 5 & 104 & Baa1 & 31 \\
\hline IKB Credit Linked Notes 2000-1 & CLO & 10 & 0.534 & 3 & 61 & Ba2 & 33 \\
\hline LeTerage Friarce Arrope Captali I . V. & CLO & 10 & 0315 & 4 & 30 & 81 & 26 \\
\hline Landan WaIn 2002-1 FLC & CLO & 6 & 3000 & 5 & 330 & Baa2 & 70 \\
\hline Landan WTan 2002-2 FLC & CLO & 6 & 1800 & 5 & 224 & Baa2 & 70 \\
\hline ARCH ONE FINANCE LIITTED & other & 4 & 0.490 & 2 & 70 & Baa1 & 47 \\
\hline ARGON CAPIT AL PLC-SERIES 1 & other & 7 & 1382 & 5 & 53 & Baa1 & 30 \\
\hline Brooklonds Bro Ref. Livked Notes 2001-1 & other & 10 & 1000 & 3 & 100 & Baa1 & 50 \\
\hline Cofthedrill Limted & other & 5 & 0.466 & 3 & 52 & Baa1/8aa2 & 36 \\
\hline CDO Master hrestmert $2 \mathrm{SA}$ & other & 5 & 3.750 & 3 & 112 & Baa1 & 66 \\
\hline CDO Master hrestment 3 SA & other & 5 & 2500 & 3 & 86 & Baa1 & 60 \\
\hline CDO Master Hvestment SA & other & 5 & 1625 & 3 & 100 & Baa1 & 49 \\
\hline CDNEO FINANCE PF & other & 10 & 0250 & 3 & 57 & Baa2 & 34 \\
\hline 8.V. (Petro III) & other & 5 & 2320 & 5 & 232 & A3 & 103 \\
\hline Credico Fundinz S r. 1 . & other & 6 & 0.890 & 1 & 117 & Ba 1 & 30 \\
\hline Deutche Bamk - Urited Gbbalhr. Gr. CDOI & other & 5 & 1.436 & 3 & 148 & Baa1 1 & 80 \\
\hline D YNAS O 20021 LTD & other & 5 & 1000 & 3 & 100 & $A^{A}$ & 55 \\
\hline Eirles: & other & 7 & 0826 & 3 & 74 & A3 & 408 \\
\hline Fimp & other & 7 & 1069 & 3 & 59 & A 1 & 26 \\
\hline B.V.2001-1 & other & 5 & 0800 & 2 & 80 & & 50 \\
\hline Lus itmo Gobal CD O No. $1, \mathrm{pk}$ & other & 4 & 1.145 & 3 & 218 & Bas3 & 35 \\
\hline Marche Asset Pontfolio SIl & other & 3 & 0.168 & 3 & 59 & Baa1 & 12 \\
\hline Redvood CBO & other & 10 & 0300 & 3 & 100 & 82 & 45 \\
\hline ce Limited Peas & other & 5 & 0950 & 2 & 100 & Baa2 & 56 \\
\hline Vints & & 10 & 0360 & 1 & 76 & Baa2 & 36 \\
\hline |C AST 1999-1 Itd & SME CLO & 7 & 2900 & 4 & 4389 & Baa3 & 70 \\
\hline C AST 2000-1 I LA & SME & 7 & 4500 & 4 & 1991 & $8 \mathrm{Ba} 3$ & 70 \\
\hline C AST $2000-2$ ItA & SME & 7 & 2500 & 4 & 5178 & Baa3 & 95 \\
\hline HAT i & SME CLO & 5 & 2500 & 3 & 650 & $8 \mathrm{~B} 2$ & 100 \\
\hline toti ILimited & SME CLO & 5 & 2500 & 4 & 1455 & $\mathrm{Ba} 2$ & 110 \\
\hline PR OMISE- $\hat{A}_{2} 2000-1$ & SME CLO & 8 & 1000 & 5 & 1097 & Ba 1 & 90 \\
\hline $\begin{array}{l}\text { FR OMTSE } \hat{A}_{<}=00 \mathrm{~L}-1 \mathrm{DV}\end{array}$ & SME & 8 & 1818 & 6 & 1277 & Ba 1 & 124 \\
\hline From ise-c-2002-1 & SME CLO & 6 & 1500 & 5 & 4578 & Вaа3 & 90 \\
\hline 03.1 & SME CLO & 5 & 1.130 & 5 & 1512 & $\mathrm{Ba} 2$ & 80 \\
\hline mo & SME CLO & 7 & 0.850 & 4 & 100 & $B a 1$ & 85 \\
\hline & SME CLO & 8 & 2.500 & 5 & 2267 & $8 a 3^{2}$ & 80 \\
\hline 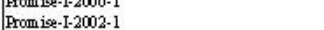 & SME & 7 & 3850 & 5 & 4172 & Bas3 & 80 \\
\hline From ise-K-2001-1 & SME CLO & 5 & 1000 & 5 & 2916 & $8 a 1 / 8 a 2$ & 100 \\
\hline From ise-Z-2001-1 & SME CLO & 8 & 1000 & 5 & 658 & Ba 1 & 85 \\
\hline
\end{tabular}

